\title{
CULTURA DE NEGÓCIOS: AMBIGÜIDADES E CONTRADIÇÕES
}

\author{
Lívia Barbosa \\ Professora do Programa de Pós-Graduação em Antropologia da UFF. \\ E-mail: livia@visualnet.com.br
}

Nas últimas duas décadas, o termo "cultura" foi associado a tópicos oriundos do universo das organizações, da administração e dos negócios, originando conceitos importantes para o entendimento e a análise da dimensão simbólica do contexto organizacional. Entre os mais conhecidos, encontram-se: cultura organizacional, cultura corporativa e cultura empresarial.

Entretanto, existe um outro grupo de conceitos que, embora menos populares, também relacionam cultura ao universo organizacional e de negócios. Esse grupo diferencia-se do anterior pela maneira que problematiza as relações entre o universo simbólico das organizações e os ambientes sociais que lhe são externos. De tal grupo fazem parte a cultura Davos e a cultura de negócios.
Cultura Davos (termo dado a partir do World Economic Summit, que se reúne anualmente na cidade de Davos) e cultura de negócios estão relacionadas aos processos culturais globais que acompanham as transações econômicas e financeiras e o universo das organizações.

Para Berger e Huntington, os criadores do termo, cultura Davos é um dos quatro processos de globalização em curso no mundo contemporâneo. Os demais seriam: cultura acadêmica, cultura mcworld e protestantismo evangélico. Esses quatro processos influenciam uns aos outros de várias maneiras e se relacionam com as culturas locais com as quais interagem.

A cultura Davos é globalizante na medida em que ocorre paralelamente aos processos econômicos globais, disseminando seus valores, suas lógicas gerencias e sua forma de "fazer negócios". Os participantes dos círculos de negócios internacionais e transnacionais, portanto uma elite, são um de seus principais mecanismos de disseminação.

Entretanto, a cultura Davos não se restringe aos escritórios e corporações, estendendo seus tentáculos para a vida familiar dos participantes. Alguns aderem inteiramente a seus princípios comportamentais básicos; outros precisam ser socializados; outros, ainda, procuram estabelecer complexos compromissos com as demandas da cultura Davos e seus vínculos e visões locais.

Cultura de negócios é um conceito complementar ao de cultura Davos. Seu foco não é o estilo de vida nem os compromissos práticos e simbólicos que os participantes dos cír- 
culos de negócios internacionais realizam. O foco da cultura de negócios é representado por diferentes tipos de processos simbólicos globais postos em andamento pelos fluxos econômicos e financeiros internacionais, suas gêneses e lógicas de produção e disseminação de informação. A cultura de negócios pode ser analisada a partir de três perspectivas distintas.

A primeira busca saber como o conhecimento sobre negócios e a melhor forma de gerenciá-los são produzidos, em que consiste essa produção, quais os canais utilizados e que agentes participam de seu processo de difusão.

A segunda perspectiva consiste em mapear os diferentes processos culturais que operam na transmissão de conhecimento e informação contidos na cultura de negócios, indicando novas semantizações que ocorrem no momento de sua aplicação em unidades geográficas, políticas e administrativas específicas.

A terceira perspectiva diz respeito aos princípios lógicos e valorativos que permeiam as informações e a teoria sobre negócios, administração e gerência.

No presente ensaio, gostaria de deter-me nessa terceira dimensão da cultura de negócios, explorando alguns de seus princípios e indicando implicações pragmáticas para a prática gerencial no Brasil.

\section{Cultura de negócios}

A cultura de negócios pode ser definida como uma série de fluxos culturais - repertórios de imagens, valores, símbolos e significados que permeiam o discurso e a atividade empresarial e gerencial das empresas transnacionais, multinacionais e/ou globalizadas.

Tais fluxos funcionam como o arcabouço ideológico do mundo em- presarial, explicando e justificando as constantes mudanças tecnológicas e gerenciais às quais as empresas foram submetidas nos últimos 20 anos.

O principal eixo que estrutura esse arcabouço é a constatação da existência de uma quebra de paradigma que transformou o mundo e o mercado local, tornando-os diferentes do que todos estavam familiarizados até então. Por meio de seus repertórios de imagens, lógicas, discursos e valores, a cultura de negócios justifica o que mudou, explica porque mudou e informa o que deve ser feito para a organização continuar sobrevivendo com sucesso.

É relevante observar que os repertórios relativos à cultura de negócios não circulam em vácuos culturais. Eles são implementados em organizações inseridas em diferentes contextos culturais, que se relacionam de forma dinâmica com os repertórios, gerando sincretismos, hibridismos e resistências em nível local. Em suma, na prática, ocorrem novas semantizações de imagens, valores, discursos e práticas que a cultura de negócios dissemina como se fossem universais e universalizantes.

Entretanto, mesmo ocorrendo essas novas semantizações, os fluxos culturais que compõem a cultura de negócios são organizados dentro de determinadas lógicas e valores presentes na forma em que o conhecimento e a informação sobre negócios são disseminados. Ou seja, esse material é "formatado" dentro de critérios que veiculam sempre da mesma maneira, por meio dos mesmos canais, um mesmo conjunto lógico e valorativo de forma implícita.

Vários aspectos da cultura de negócios podem ser salientados, como por exemplo:

- uma condição sempre presente de foco no curto prazo;
- uma abordagem "triunfalista" na apresentação das tecnologias gerenciais, que supostamente conduzem as organizações e seus líderes ao sucesso;

- uma valorização do adestramento em detrimento da aprendizagem;

- uma visão esquemática da vida organizacional, que surge desbastada de sua complexidade, sob a forma de conceitos monolíticos e reducionistas;

- um uso abusivo de métodos audiovisuais em que a apresentação e sistematização dos dados e dos problemas são confundidas com a interpretação dos fatos; e

- a utilização abundante de metáforas cujas interpretações não são deixadas ao receptor, mas já lhe chegam interpretadas pelo autor; uma valorização da novidade como se esta fosse o mesmo que mudança.

\section{Pragmatismo}

Dentre os critérios que "formatam" a informação e o conhecimento sobre o mundo dos negócios, um dos que mais se destacam é a lógica pragmática. De fato, o pragmatismo da cultura de negócios aparece sob diferentes formas.

A primeira forma caracteriza-se pela exigência que todo e qualquer conhecimento deve ter para a realidade organizacional e de negócios. A cultura de negócios é voltada para a ação, para o "fazer acontecer". Todo e qualquer conhecimento, portanto, deve ser um instrumento que possibilite a intervenção na realidade para fins de alterá-la segundo objetivos previamente estabelecidos. O conhecer por conhecer, a reflexão de cunho teórico, a investigação mais profunda e de longo prazo têm pouco lugar nesse universo.

Os próprios termos utilizados no vocabulário da cultura de negócios - como ferramenta, tecnologia e ins- 
trumento - são indicadores de tal ideologia intervencionista. Os títulos de artigos e livros constituem outro bom exemplo da necessidade instrumental da cultura de negócios, que se aplica mesmo em dimensões em que não se pensaria ser isso possível, como é o caso da cultura organizacional. Um ótimo exemplo para esse ponto é o capítulo Managing culture at the bottom, de Tim R. V. Davis, no livro Gaining control of the corporate culture, coordenado por Ralph Kilmann e colaboradores.

Portanto, cada nova ferramenta gerencial tende a criar um novo tipo de tecnólogo, alguém que é especialista na implantação de uma determinada ferramenta gerencial, que ensina "passo a passo" os segredos do novo conhecimento. Os tecnólogos colocam sua metodologia e experiência a serviço da comunidade empresarial. Entre os mais conhecidos na atualidade estão os tecnólogos da diversidade, dentre os quais sobressaem-se Ted Child e Laura Nile.

Esse processo de transferência de tecnologia é apoiado em dados objetivos e, aparentemente, científicos. Os tecnólogos procuram apresentar de forma numérica e estatística as vantagens e os resultados da nova tecnologia. Conseqüentemente, contabilizar, avaliar, medir e verificar são dimensões ideologicamente importantes e permanentemente enfatizadas. Por outro lado, dimensões mais intangíveis da realidade como, por exemplo, cultura política, capital de relacionamento e capital social são, de imediato, transformadas em "variáveis" e sobre elas debruçamse todos, com o objetivo de encontrar as ferramentas adequadas para medi-las.

Uma outra dimensão do pragmatismo da cultura de negócios surge no pouco interesse pela origem, pelo agente do conhecimento e pelo tipo do conhecimento. Isso significa que a caracterização do conhecimento não desempenha um papel relevante, desde que efetividade e resultados sejam prometidos.

Portanto, no universo dos negócios e das empresas, encontramos saberes e personagens das mais diferentes procedências. Temos desde o conhecimento científico da física quântica e da matemática do caos, até abordagens trazidas por psicólogos, antropólogos, rabinos, poetas, administradores, engenheiros, astrólogos e numerólogos, entre muitos outros.

Filosofias inteiramente contraditórias de como devem ser as práticas gerenciais, a organização das empresas e o tipo de conhecimento que devemos utilizar convivem lado a lado em uma mesma organização. Métodos de treinamento de guerra, passando por técnicas de auto-ajuda e "filosofias new age", encontram tanto espaço quanto as ferramentas da qualidade e da reengenharia.

A importação de conhecimento e conceitos de outras disciplinas ou saberes é feita sem qualquer reflexão sobre as respectivas genealogias, precisão e adequação ao mundo dos negócios e à gerência.

Em um levantamento realizado pela empresa de consultoria Bain \& Company em todo o mundo, 25 tecnologias gerenciais foram identificadas como as mais usadas, sendo que as empresas utilizam em média cerca de 13 ou 14 delas simultaneamente. Diante desses números, devemos parar para refletir sobre o estresse e o ritmo do "adestramento" a que as pessoas são submetidas pela introdução constante de novas tecnologias gerenciais, cuja consistência e efetividade temos bons motivos para duvidar.
Em termos epistemológicos, poderíamos dizer que a cultura de negócios ignora o contexto da descoberta, privilegiando o contexto da justificativa. Ou seja, os méritos lógicos das teorias, em sua capacidade de intervenção e explicação da realidade, são as variáveis consideradas relevantes para a incorporação de uma nova ferramenta gerencial. Entretanto, o contexto da justificativa não é, como vimos acima, alvo de qualquer escrutínio que avalie seus critérios epistemológicos e heurísticos.

\section{Lógica e racionalidade}

Além de pragmático, o mundo dos negócios apresenta-se como um universo no qual predominam a lógica e a racionalidade nas decisões. Por isso, entende-se que estas são determinadas pelas necessidades intrínsecas do próprio objeto - ou seja, encontram-se na natureza das coisas. Isso significa que as decisões de negócios são apresentadas como impessoais, objetivas e racionais, inteiramente desencarnadas dos contextos, das emoções e visões de mundo das pessoas que delas participam. Tal racionalidade reforça, ainda mais, a tentativa de representação numérica da realidade. Estatísticas e números são igualados à verdade dos fatos e a taxa de ocorrência de um determinado fenômeno ou opinião é entendida como seu significado.

A racionalidade e objetividade na apresentação dos fatos e resultados, que comprovariam a efetividade das tecnologias gerenciais, não significam, contudo, que os pressupostos epistemológicos e os métodos de validação sejam objetos de uma análise cuidadosa. O que ocorre geralmente é o contrário - o que chega a ser profundamente irônico.

Em um ambiente culturalmente obcecado por resultados concretos e 
objetivos, no qual os agentes procuram revestir os números obtidos com uma áurea de cientificidade, a forma em que esses números são obtidos quase nunca é discutida. Assim, tabelas, estatísticas e resultados são apresentados e utilizados como indicadores de sucesso sem que qualquer reflexão mais ampla seja realizada.

Uma ilustração para essa questão é dada por uma afirmação da revista Forbes, de que as empresas norte-americanas que possuíam as melhores políticas de diversidade foram as que obtiveram os melhores resultados no mercado de ações, como prova da eficácia das tecnologias de diversidade. De fato, tal afirmação não resiste a uma análise mais profunda.

\section{Culto a novidades}

Uma outra face do pragmatismo da cultura de negócios, que contrasta muito com a cultura acadêmica, é o descarte sistemático de teorias vis a vis às suas exegeses. Enquanto toda nova teoria no mundo acadêmico começa sua vida confrontando explicitamente alguma teoria anterior, ou pelo menos deslocando-a para a periferia do sistema, nada de semelhante observa-se na cultura de negócios. Nesta, o paralelismo teórico e tecnológico impera. A chegada de uma novidade ao mercado não implica necessariamente o desalojamento das atuais ferramentas gerenciais em uso. Significa apenas mais uma à disposição, como a mencionada pesquisa da Bain \& Company demonstra.

É claro que em alguns casos podem existir controvérsias. Mas, nessas circunstâncias, basta assumir o engano e escrever um novo livro para justificar a ausência dos resultados prometidos e comprovados anteriormente por números, tabelas e gráficos. Dentro de tal perspectiva, os casos da reengenharia e do downsizing são exemplares.
Champy, no primeiro capítulo de seu livro Reengenharia da gerência: o mandato da nova liderança, afirma que a reengenharia está em apuros. Diz o autor: "Não é fácil para mim admitir isso. Fui uma das duas pessoas que introduziram o conceito". Então, prossegue dizendo que a amostragem do estudo que realizou com $497 \mathrm{em}-$ presas norte-americanas revela que, em $71 \%$ dos casos, a defasagem dos participantes em relação aos marcos propostos pela reengenharia é de cerca de 30\%. Concluindo, Champy afirma que não tinha em mente essa revolução parcial e que ele acredita que metade de uma revolução pode ser até pior que nenhuma revolução. Daí ter escrito a Reengenharia da gerência, justamente para cobrir tais falhas. Parece, contudo, que os resultados da reengenharia foram bem mais dramáticos do que ele quer fazer crer, tanto em termos de impactos sobre a produtividade como em termos de traumas humanos.

O caso de Tomasko é semelhante ao de Champy. Depois do sucesso do livro Downsizing: reformulando e redimensionando a organização para ao futuro, que, junto com a reengenharia foi o responsável por uma onda de reestruturações e cortes sem precedentes no mundo organizacional, o autor escreve um segundo livro: Crescer, não destruir. Como o próprio nome indica, nesse último livro é feita uma apologia do processo inverso do defendido em Downsizing. Segundo o autor, Downsizing foi utilizado como uma panacéia pelas organizações, quando muitas vezes não se aplicava. Ele agora chama a atenção para outros aspectos desconsiderados no furor do modismo.

O fato é que os autores dos chamados modismos gerenciais ganham gigantescas somas com livros, palestras e projetos de consultoria. Para as pessoas-alvo desses mesmos modismos, ficam os custos, como a perda do emprego ou a desestruturação da família.

\section{Observações finais}

O pragmatismo da cultura de negócios, aliado a outras lógicas e valores como o reducionismo e o culto da novidade -, faz do mundo organizacional um espaço aberto à informação, à experimentação e à metodologia pouco convencionais, dotando-o de excepcional dinamismo.

Todo mês, uma nova tecnologia desponta, movimentando o mercado editorial e de consultores, vendendo sucesso a preços módicos e provocando o "adestramento" de milhares de pessoas, que há bem pouco tinham sido introduzidas a "outras novas mudanças e receitas de sucesso".

No caso da sociedade brasileira, esse movimento de "entre e sai" de novas tecnologias é ainda mais dramático do que nos Estados Unidos, produtor de quase todas elas. Entre nós, a necessidade de "ser moderno" faz com que não deixemos de lado nada novo que se nos apresenta. Assim, expomo-nos a um alto nível de estresse, que é inversamente proporcional aos resultados obtidos.

Submeter gerentes e executivos a treinamentos de mudança organizacional baseados em tecnologias gerenciais de sustentação empírica e/ou científica duvidosa, ou em sucessos editorias do tipo Quem mexeu no meu queijo, é menosprezar sua capacidade intelectual.

Tecnologias gerencias são, sem dúvida alguma, instrumentos importantes no mundo corporativo contemporâneo. Contudo, seu uso não precisa ser feito às custas do embotamento intelectual, do cerceamento da criatividade e do adestramento das pessoas.

\footnotetext{
Pensata recebida em 01/07/2002. Aprovada em 08/07/2002.
} 